\title{
Agostic Interaction of the Smallest Zirconium Methylidene Hydride: Reproduction of the Distorted Structure Experimentally Observed in Matrix Infrared Spectra
}

\author{
Han-Gook Cho* and Byeong-Seo Cheong \\ Department of Chemistry, Lniversity of Incheon, Incheon 402-749, Korea. ${ }^{*}$-mall hgcaincheon.ack kr \\ Received Wovember 17, 2008, Accepted December 11, 2008
}

Key Words: Agostic interaction. Electron delocalization. Methylidene complex. NBO. Occupation number

Many transition metals. including lanthanides and actinides. form $\mathrm{C}-\mathrm{H}(\mathrm{X})$ insertion products and also high oxidation-state complexes with a carbon-metal multiple bond via following $\mathrm{H}(\mathrm{X})$ migration in reactions with small hydrocarbons and halomethanes. ${ }^{1,2}$ These new breed of metal complexes, small cousins of metal complexes with large ligands. often show unique structures and photochemical properties. Particularly the methylidene complexes often show markedly distorted structures for one of the hydrogen atoms to position close to the metal atom (agostic structure), ${ }^{2,3}$ These small complexes are more amenable to higher level of theoretical investigations and, therefore, considered as ideal systems to inv estigate the distinct stnictures and ligand effects of the transition-metal complexes with larger ligands.

While many transition-metal complexes with large ligands are often agostic, the experimental evidences are often elusive particularly in IR spectra. ${ }^{1 \cdot 3}$ Recently $\mathrm{CH}_{2}=\mathrm{Z}_{\mathrm{rH}}$. the smallest possible methylidene hydride complex, is generated from reactions of laser-ablated $\mathrm{Zr}$ atoms and methane isotopomers in excess neon and argon. ${ }^{6}$ The strong symmetric and antisymmetric stretching $\mathrm{ZrH}_{2}$ absorptions, along with the deuterium counterparts, are observed along with other lower frequency absorptions. More importantly the two sets of $\mathrm{Zr}-\mathrm{H}$ as well as $\mathrm{Zr}-\mathrm{D}$ stretching absorptions of the half deuterated species are observed between the strong symmetric and anti-symmetric stretching bands, a strong IR evidence for the agostic structure.

Normally the decoupled M-H stretching bands appear at the middle of the symmetric and anti-symmetric stretching bands if the two $\mathrm{M}-\mathrm{H}$ bonds are identical. The two sets of strong absorptions observed between the symmetric and anti-symmetric $\mathrm{ZrH}_{2}$ and $\mathrm{ZrD}_{2}$ stretching absorptions, therefore. indicate that the molecule is markedly distorted such that the decoupled M-H stretching frequencies differ as large as 16.5 $\mathrm{cm}^{-1}$ in a Ne matrix. ${ }^{6}$ Furthermore. electronic structure calculations show that $\mathrm{CH}_{2}=\mathrm{ZrH}_{2}$ has a highly distorted $\mathrm{C}_{1}$ strnicture. where the methylene group is considerably distorted. and the $\mathrm{Zr}$ atom is located at the apex of the trigonal py ramid structure. ${ }^{-36}$ The 8 possible isotopomers with $C_{1}$ symmetry shown in Scheme 1 are grouped into four sets $(1-2.3-5,4-6$. and 7-8). the two configurations in each set having essentially the same lydrogen stretching frequencies. ${ }^{6}$ Calculations with the planar $\mathrm{C}_{\text {Iv }}$ symmetry constraint generate two imaginary frequencies (the $\mathrm{ZrH}_{2}$ wagging and $\mathrm{CH}_{2}$ rocking modes).

In this study we have carried out a theoretical investigation at various levels in an effort to properly understand the details of the agostic interactions. which often play an important role for the structures of high oxidation-state transition-metal complexes. Density functional theory (DFT) calculations were carried out using the Gaussian 03 package. the B3LYP density functional. $6-311++\mathrm{G}(3 \mathrm{df} .3 \mathrm{pd})$ basis sets for $\mathrm{C}, \mathrm{H}$. and SDD pseudopotential and basis for $\mathrm{Zr}$ (28 electron core). BPW9l functional. MP2, and more rigorous CCSD and CCSD(T) calculations were also done to complement the hybrid functional results. NBO analyses were also carried out to trace the extent of electron delocalization. ${ }^{8}$

Traditionally the agostic (meaning "toward") interaction has been explained as electron donation from the nearby $\mathrm{C} \cdot \mathrm{H}$ bond to the electron-deficient metal center. ${ }^{4.5}$ The strength (typically estimated $<20 \mathrm{kcal} / \mathrm{mol}$ ) and geometry of these bonds depend on the energy and disposition of the vacant metal orbitals relative to the $\mathrm{C}-\mathrm{H}$ bonding orbitals and the steric effects imposed to the linkage., Recently Sherer and McGrady have claimed that it is in fact a negative hyperconjugative delocalization of $\mathrm{M}-\mathrm{C}$ bonding electrons in $\mathrm{d}^{\mathrm{b}}$ complexes to stabilize the carbon-metal bond. More recently Berkaine et al. reported that the Group 4 metal methylidene systems. particularly $\mathrm{CH}_{2}=\mathrm{TiH}_{2}$, are essentially single configuration problems, and the occupation number of the $\mathrm{M}-\mathrm{H}$ bond diagonal to the agostic $\mathrm{C}-\mathrm{H}$ bond increases with the distortion while that of the $\mathrm{C}-\mathrm{H}$ bond decreases. suggesting strong electron delocalization of the agostic $\mathrm{C}-\mathrm{H}$ bond to the metalhydrogen anti-bond $\left(\sigma^{*}(\mathrm{M}-\mathrm{H})\right)^{9}$

The B3LYP/6-311++G(3df.3pd)/SDD structure of $\mathrm{CH}_{2}=$ $\mathrm{ZrH}_{2}$ in its singlet ground state is shown in Figure 1 with the natural orbitals mostly involved in the agostic interaction. The methylene group is markedly rotated such that $\angle \mathrm{H}_{3} \mathrm{CZr}$ and $\mathrm{r}\left(\mathrm{H}_{1} \cdots \mathrm{Zr}\right)$ are $92.9^{\circ}$ and $2.300 \AA$. and the $\mathrm{C}-\mathrm{H}_{1}$ bond is elongated to $1.115 \mathrm{~A}$. The $\mathrm{Zr}$ atom is at the apex of the asymmetric trigonal pyramid formed by the $\mathrm{C}, \mathrm{Zr}$, and two hydrogen atoms (the $\angle \mathrm{CZrH}_{2}, \angle \mathrm{CZrH}_{4}$, and $\angle \mathrm{H}_{2} \mathrm{ZrH}_{4}$ are 105.9 .110 .2 , and $116.4^{\circ}$. respectively). The related geometric parameters at various levels of theory and the natural occupation numbers are listed in Table 1, which shows that the MP2 structure with the same basis is most agostic $\left(\angle \mathrm{H}_{1} \mathrm{CZr}=80.1^{\circ}\right)$ while the BPW9l structure is in between. The CCSD and CCSD(T) agostic angles are 86.1 and $83.8^{\circ}$, comparable to that of the BPW91 structure $\left(85.5^{\circ}\right)$

The NBO occupation number of the agostic $\mathrm{C} \cdot \mathrm{H}_{3}$ bond (1.924) estimated at the B3LYP/6-311++G(3df.3pd)/SDD level is considerably lower than the that for the $\mathrm{C}-\mathrm{H}_{2}$ bond 
(1.993), whereas that of the $\mathrm{Zr}-\mathrm{H}_{4}$ anti-bonding orbital $\left(\sigma^{*}\right.$ $\left(\mathrm{Zr}-\mathrm{H}_{4}\right)$ ) is 0.037 . in line with the recent results of Berkaine $e t$ $a^{5}$ In addition, the occupation number for the $\mathrm{Zr}$ d-orbital is 0.060 . showing the electron delocalization from the $\mathrm{C}-\mathrm{H}$ bond occurs to the empty $\mathrm{Zr}$ d-orbital as well. Computation with the $\mathrm{C}_{2}$ constraint and same basis set gives the $\mathrm{C}-\mathrm{H}$ bonding, $\mathrm{Z} \mathrm{r}-\mathrm{H}$ anti-bonding. and $\mathrm{Zr}$ d-orbital occupation numbers of 1.988 . 0.018 , and 0.006 (not listed in Table 1), respectively. As a result the electron delocalization of the $\mathrm{Zr}-\mathrm{H}$ orbital in the $\mathrm{C}_{\mathbf{A}}$ structure is also far less important (only $1.6+\mathrm{kcal} / \mathrm{mol}$ ).

Table 1 also shows that the more agostic BPW91 and MP2 stnictures are accompanied with the more electron delocalization. The B3LYP. BPW91, and MP2 delocalization energies (with B3LYP/6-311+G(3df.3pd)/SDD) to the $\sigma^{*}\left(\mathrm{Zr}-\mathrm{H}_{4}\right)$ bond increase $4.9,1.1$, and $8.5 \mathrm{kcal} / \mathrm{mol}$. respectively. from the $\mathrm{C}_{2 \mathrm{v}}$ (constrained) to $\mathrm{C}_{1}$ structure, and those to the $\mathrm{Z}_{\mathrm{r}} \mathrm{d}$-orbital increase 13.3 .23 .7 . and $32.7 \mathrm{kcal} / \mathrm{mol}$. respectively. Clearly the delocalization to the $\mathrm{Zr}$ d-orbital is substantially more important in most cases than to the $\mathrm{Zr}-\mathrm{H}_{4}$ anti-bond. While the increase in the sum of the B3LYP delocalization energies $(\sim 18$ $\mathrm{kcal} / \mathrm{mol}$ ) is comparable to the previously estimated values. ${ }^{4.5}$ the BPW9I and MP2 values are noticeably higher. The agostic distortion is also associated with the shorter $\mathrm{C}=\mathrm{Zr}$ bond. in line with the recent report that the agostic interaction arises from negative hyperconjugation to stabilize the carbon-metal bond.

While the details still need to be investigated further. these NBO results strongly indicate that the agostic structure, which is in fact counterintuitive. is a result of molecular distortion for more effective donation of the $\mathrm{C}-\mathrm{H}$ bond electrons to the $\mathrm{Zr}-\mathrm{H}_{\uparrow}$ anti-bonding and empty $\mathrm{Zr}$ d-orbitals. The present results are also consistent with the previous investigations for the causes of the intra-molecular interaction. electron donation from the $\mathrm{C}-\mathrm{H}$ bond in proximity to the empty metal d-orbital. ${ }^{3 .+4}$ electron delocalization for stabilization of the carbon-metal bond ${ }^{5}$ and occupancy transfer to the $\sigma^{*}(\mathrm{Zr}-\mathrm{H})$ orbital.

Interestingly enough. Table 1 also shows that removal of the diffusion functions from the basis set yields only negligible effects to the agostic structure. whereas the polarization functions play a major role for the agostic distortion at all levels of theory used in this study. Without the polarization functions. the geometry optinizations end up with a $\mathrm{C}_{\mathrm{s}}$ structure with the two equal $\mathrm{Zr}-\mathrm{H}$ bonds. in line with the recent matrix infrared study. ${ }^{-}$This clearly shows the importance the polarization function in reproducing electron delocalization in a transition-metal complex. Also shown in Table 1 is that the polarization functions for $\mathrm{C}$ is more inportant than for $\mathrm{H}$. Inclusion of polarization functions for $\mathrm{C}$ but not for $\mathrm{H}$ leads to more agostic distortion and electron delocalization of the $\mathrm{C}-\mathrm{H}$ bond than the reverse. reconfinming that the distinct inclination of the $\mathrm{H}$ atom is a result from the interaction of the $\mathrm{C}-\mathrm{H}$ bond. not the $\mathrm{H}$ atom alone. . $^{2.5 .9}$

Polarization functions (one or three sets of f-orbitals) are also added to the SDD effective core potential and basis." Table I shows that addition of the polarization functions slightly increases the agostic distortion as well as the extent of the electron delocalization. Moreover, the observed $\mathrm{Zr}-\mathrm{H}$ and $\mathrm{Z}$-D stretching frequencies for the $\mathrm{CH}_{2}=\mathrm{ZrH}_{2}$ isotopomers are best reproduced by the basis set with most polarization functions. For example, the $\mathrm{Zr}-\mathrm{H}$ and $\mathrm{Zr}$-D stretching modes of 3 and 5 are predicted 8.4 and $17.5 \mathrm{~cm}^{-1}$ above the $\mathrm{ZrH}_{2}$ and $\mathrm{ZrD}_{2}$ anti-symmetric stretching modes of $\mathbf{1}$ and $\mathbf{8}$. respectively

Table 1. Geonetrical Parameters, Occupation numbers, and Delocalization Energies Related to the Agostic Interaction of $\mathrm{CH}_{2}=\mathrm{Zr} \mathrm{H}_{2}$ in $\mathrm{Its}$ Ground Singlet State

\begin{tabular}{|c|c|c|c|c|c|c|c|}
\hline Method & $\begin{array}{l}\mathrm{r}\left(\mathrm{C}-\mathrm{H}_{1}\right) / \\
\mathrm{r}\left(\mathrm{C}-\mathrm{H}_{2}\right)\end{array}$ & $\begin{array}{l}<\mathrm{H}_{3} \mathrm{CZr} / \\
<\mathrm{H}_{2} \mathrm{CZr}\end{array}$ & $\mathrm{r}(\mathrm{C}=\mathrm{Z} \mathbf{r})$ & $\begin{array}{l}<\mathrm{CZrH}_{3} / \\
<\mathrm{C} Z \mathrm{LrH}_{4}\end{array}$ & $\begin{array}{l}\sigma\left(\mathrm{C}-\mathrm{H}_{1}\right) / \\
\sigma\left(\mathrm{C}-\mathrm{H}_{2}\right)^{b}\end{array}$ & $\begin{array}{c}\sigma^{*}\left(\mathrm{Zr}-\mathrm{H}_{4}\right)^{b} / \\
\mathrm{DE}^{c}\end{array}$ & $\begin{array}{c}\mathrm{LP}^{*}(\mathrm{Zr})^{b} / \\
\mathrm{DE}^{c}\end{array}$ \\
\hline B3LYP/6-311G/SDD & $1.097 / 1.097$ & $123.5 / 123.5$ & 1.981 & $109.5 / 109.5$ & $1.974 / 1.974$ & $0.021 / 2.39$ & $0.030 / 2.63$ \\
\hline B3LYP/6-311++G/SDD & $1.097 / 1.097$ & $123.5 / 123.5$ & 1.982 & $109.5 / 109.5$ & $1.975 / 1.975$ & $1.021 / 2.24$ & $0.030 / 2.55$ \\
\hline B3LYP/6-311++G(3df,3pd), 6-311++G/SDD & $1.111 / 1.083$ & $96.3 / 150.0$ & 1.968 & $106.2 / 110.7$ & $1.935 / 1.985$ & $0.035 / 5.69$ & $0.051 / 10.81$ \\
\hline B3LYP/6-311++G, 6-311++G(3dt,3pd)/SDD & $1.117 / 1.086$ & $94.0 / 152.7$ & 1.955 & $106.5 / 111.0$ & $1.928 / 1.986$ & $0.038 / 6.84$ & $0.056 / 13.14$ \\
\hline B3LYP/6-311G(3df,3pd)/SDD & $1.116 / 1.084$ & $92.9 / 153.5$ & 1.954 & $105.9 / 110.1$ & $1.922 / 1.986$ & $0.083 / 6.85$ & $0.061 / 14.37$ \\
\hline B3LYP/6-311++G(3df,3pd)/SDD & $1.115 / 1.084$ & $92.9 / 153.5$ & 1.955 & $105.9 / 110.2$ & $1.924 / 1.993$ & $0.037 / 6.50$ & $0.060 / 13.87$ \\
\hline $\mathrm{B} 3 \mathrm{LYP} / 6-31 \mathrm{l}+\mathrm{G}(3 \mathrm{df}, 3 \mathrm{pd}) / \mathrm{SDD}(\mathrm{t})^{\prime}$ & $1.117 / 1.084$ & $91.7 / 154.8$ & 1.946 & $106.5 / 111.6$ & $1.921 / 1.986$ & $0.040 / 7.61$ & $0.060 / 14.33$ \\
\hline B3LYP/6-311++G(3df,3pd)/SDD(3f $)^{\prime}$ & $1.118 / 1.084$ & $91.2 / 155.4$ & 1.943 & $106.8 / 112.3$ & $1.919 / 1.986$ & $0.041 / 8.13$ & $0059 / 14.49$ \\
\hline $\mathrm{B} 3 \mathrm{LYP} / 6-311++\mathrm{G} / \mathrm{SDD}(3 \mathrm{f})$ & $1.098 / 1.098$ & $123.6 / 123.6$ & 1.969 & $111.3 / 111.3$ & $1.975 / 1.975$ & $0.021 / 2.64$ & $0.027 / 2.43$ \\
\hline BPW91/6-311++G/SDD & $1.105 / 1.105$ & $123.5 / 123.5$ & 1.981 & $108.2 / 108.2$ & $1.970 / 1.970$ & $0.020 / 1.79$ & $0.040 / 2.54$ \\
\hline BPW91/6-311G(3df,3pd)/SDD & $1.135 / 1.091$ & $85.5 / 161.4$ & 1.943 & $103.8 / 104.5$ & $1.878 / 1.983$ & $0.035 / 4.66$ & $0.114 / 24.70$ \\
\hline BPW $91 / 6-311++\mathrm{G}(3 \mathrm{df}, 3 \mathrm{pd}) / \mathrm{SDD}$ & $1.135 / 1.091$ & $85.5 / 161.4$ & 1.943 & $103.8 / 104.5$ & $1.879 / 1.984$ & $0.034 / 4.26$ & $0.113 / 24.22$ \\
\hline $\mathrm{MP} 2 / 6-311++\mathrm{G} / \mathrm{SDD}$ & $1.103 / 1.103$ & $122.7 / 122.7$ & 1.995 & $111.3 / 111.3$ & $1.984 / 1.984$ & $0.023 / 3.81$ & $0.012 / 2.17$ \\
\hline $\mathrm{MP} 2 / 6-311 \mathrm{G}(3 \mathrm{df}, 3 \mathrm{pd}) / \mathrm{SDD}$ & $1.133 / 1.081$ & $80.1 / 166.6$ & 1.926 & $104.5 / 109.3$ & $1.898 / 1.992$ & $0.053 / 13.19$ & $0.074 / 34.83$ \\
\hline $\mathrm{MP} 2 / 6-311++\mathrm{G}(3 \mathrm{de}, 3 \mathrm{pd}) / \mathrm{SDD}$ & $1.133 / 1.082$ & $80.1 / 166.7$ & 1.927 & $104.6 / 109.5$ & $1.900 / 1.992$ & $0.052 / 13.34$ & $0.071 / 33.60$ \\
\hline $\mathrm{CCSD} / 6-\hat{3} 11++\mathrm{G}(3 \mathrm{df}, \hat{\beta} \mathrm{pd} / \mathrm{SDD}$ & $1.124 / 1.082$ & $86.1 / 162.2$ & 1.942 & $108.1 / 117.9$ & $1.928 / 1.992$ & $0.055 / 20.40$ & $0.029 / 11.82$ \\
\hline $\operatorname{ccsD}(1) / 6-311++\mathrm{G}(3 \mathrm{df}, 3 \mathrm{pd}) / \mathrm{SDD}$ & $1.130 / 1.084$ & $83.8 / 164.1$ & 1.947 & $106.7 / 115.0$ & $1.919 / 1.992$ & $0.054 / 18.10$ & $0.043 / 18.48$ \\
\hline
\end{tabular}

${ }^{~}$ Bond lengths and angles are in $\AA$ and degree, and delocalization energies in $\mathrm{kcal}$ mol. "Occupation number. 'Delocalization energy. ${ }^{\mathrm{C}} \mathrm{H}$ and $\mathrm{C}$ with and without polarization functions. ${ }^{e} \mathrm{H}$ and $\mathrm{C}$ withont and with polarization functions. 'Polarization functions ( $\mathrm{f}$-orbitals) added to the $\mathrm{Zr}$ basis. ${ }^{\mathrm{IJ}}$ 
<smiles>C=C</smiles>

1<smiles>[2H]C=[Z]([2H])[2H]</smiles><smiles>OC=CO</smiles>

3<smiles>[2H][Z]([2H])[2H]</smiles><smiles>[2H]C=CO</smiles><smiles>C=C(O)O</smiles><smiles>[2H]C=[Zr][2H]</smiles>

6

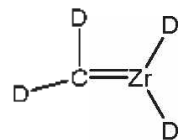

8
Scheme 1

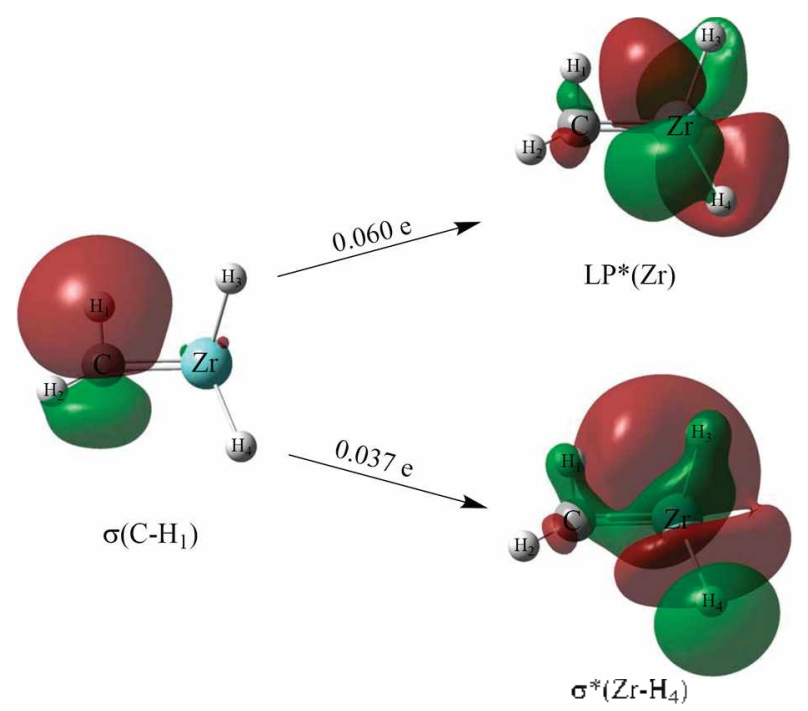

Figure 1. Delocalization of the natural $\mathrm{C}-\mathrm{H}_{1}$ bonding electrons to the $\mathrm{Zr}$ d- and $\mathrm{Zr}-\mathrm{H}_{+}$anti-bonding orbitals.

(Scheme 1). They are observed 8.3 and $17.0 \mathrm{~cm}^{-1}$ above the strong $\mathrm{ZrH}_{2}$ and $\mathrm{ZrD}_{2}$ anti-symmetric stretching absorptions at 1546.2 and $1112.3 \mathrm{~cm}^{.1}{ }^{.6}$ Likewise the $\mathrm{Zr}-\mathrm{H}$ and $\mathrm{Zr}-\mathrm{D}$ stretching modes of 4 and 6 are predicted 27.3 and $3.6 \mathrm{~cm}^{-1}$ above the strong anti-symmetric modes. and they are observed 24.8 and $4.0 \mathrm{~cm}^{-1}$ above.

However. the polarication functions for $\mathrm{C}$ and $\mathrm{H}$ are still essential to reproduce the agostic structure even when the polarization functions are added to the $\mathrm{Z}_{\mathrm{r}}$ basis set: computation with polarization functions for $\mathrm{Z}_{\mathrm{r}}$ and none for $\mathrm{C}$ and $\mathrm{H}$ also leads to a $\mathrm{C}_{3}$ structure with two equal $\mathrm{C}-\mathrm{H}$ bonds (no agostic distortion).
In conclusion, the NBO analyses show that the agosticdistortion of the smallest $\mathrm{Zr}$ methylidene hydride $\left(\mathrm{CH}_{2}=\mathrm{ZrH}_{2}\right)$ is accompanied with electron delocalization to both the $\sigma^{*}\left(\mathrm{Zr}-\mathrm{H}_{4}\right)$ bond and $\mathrm{Zr}$ d-orbital. The increases in occupation number and delocalization energy of the $\mathrm{Zr}$ d-orbital are significantly ligher than those of the $\sigma^{*}\left(\mathrm{Zr}-\mathrm{H}_{4}\right)$ bond. The BPW91. MP2, and CCSD methods produce more distorted structures and electron delocalization energies than the B3LYP method. The polarization functions for $\mathrm{H}$ and $\mathrm{C}$ are essential to reproduce the agostic distortion. of which the latter is more important than the former. Conputations without the polarization functions lead to a $\mathrm{C}_{3}$ structure with two equal $\mathrm{C}-\mathrm{H}$ bonds and insignificant delocalization energy. Addition of the polarization functions for $\mathrm{Zr}$ increases the agostic interaction and best reproduces the vibrational characteristics as well.

Acknowledgments. This work was supported by the 2008 SCI Research Fund from the College of Natural Sciences. University of Incheon

\section{References}

1. (a) Billups, W. E.; Konarski, M. M.; Hauge, R. H.; Margrave, J. L. J Am Chem. Soc. 1980, 102, 7393 (b) Lee, Y. K. Manceron. L.: Papai, I J. Phis. Chent. A 1997, 101, 9650.

2. Andrews, L.; Cho, H.-G. Orgonontetallics 2006, 25,4040, and references therein.

3. von Frantzius, G.; Streubel, R: Brandhorst, K.; Grunenberg, I. Organometalics 2006, 25, 118 , and references therein.

4. (a) Schrock, R. R. Chen. Kew, 2002, 102, 145. (b) Wada, K: Craig; B.; Pamplin, C. B.; Legzdins, P.; Patrick, B. O.; Tsyba, I; Ball, R. J. Am. Chem. Soc. 2003, 125, 7035. (c) Ujaque, G.; Cooper, A. C.: Maseras, F; Eisenstein, O.; Caulton, K. G. J. Ant. Chem. Soc. 1998, 120, 361. (d) Roos, B. O.; Lindh, R.: Cho, H.-G.; Andrews, L. J. Phys. Chem. $4 \mathbf{2 0 0 7}, 11,6420$.

5 Scherer, W.: McGrady, G. S. Angen. Chem. Int Ed. 2004, 43, 1782 .

6. Cho, H.-G; Wang, X:; Andrews, L. J. Am. Chem. Soc. 2005, 127,465 .

7. Frisch, M. T. et al. Gaussian 03, Revision C.02; Gaussian1, Inc: Pittsburgh, PA, 2003 and references therein.

8. Reed, A. E.: Curtiss, L. A.: Weinhold, F. Chem. Rer, 1988, 88 , 899 , and references therein.

9. Berkaine, N.: Reinhardt, P.: Alikhani, M. E. Chem. Phus. 2008. 343,241

10. (a) Andrae, D.: Haeussemann, U.: Dolg, M.: Stoll, H.; Preuss, H. Theor Chim .Acta 1990, 77, 123, (b) Ehlers, A. W.: Bohme, M.; Dapprich, S.; Gobbi, A.; Hollwarth, A.; Jonas, V: Kohler, K. F.: Stegmann, R.: Veldkamp, A.: Frenking, G. Chem Phns Lett. 1993, 208, 111 